\title{
Incorporating objectives of stakeholders in strategic planning of urban water management
}

Skrydstrup, Julie; Madsen, Herle Mo; Löwe, Roland; Gregersen, Ida Bülow; Pedersen, Agnethe Nedergaard; Arnbjerg-Nielsen, Karsten

Published in:

Urban Water Journal

Link to article, DOI:

$10.1080 / 1573062 X .2020 .1748204$

Publication date:

2020

Document Version

Peer reviewed version

Link back to DTU Orbit

Citation (APA):

Skrydstrup, J., Madsen, H. M., Löwe, R., Gregersen, I. B., Pedersen, A. N., \& Arnbjerg-Nielsen, K. (2020). Incorporating objectives of stakeholders in strategic planning of urban water management. Urban Water Journal, 17(2), 87-99. https://doi.org/10.1080/1573062X.2020.1748204

\section{General rights}

Copyright and moral rights for the publications made accessible in the public portal are retained by the authors and/or other copyright owners and it is a condition of accessing publications that users recognise and abide by the legal requirements associated with these rights.

- Users may download and print one copy of any publication from the public portal for the purpose of private study or research.

- You may not further distribute the material or use it for any profit-making activity or commercial gain

- You may freely distribute the URL identifying the publication in the public portal 


\section{Incorporating objectives of stakeholders in strategic planning of urban 2 water management}

3 Julie Skrydstrup ${ }^{a *}$, Herle Mo Madsen ${ }^{a}$, Roland Löwe ${ }^{\text {a }}$, Ida Bülow

4 Gregersen $^{\mathrm{b}}$, Agnethe Nedergaard Pedersen ${ }^{\mathrm{c}}$ and Karsten Arnbjerg-Nielsen ${ }^{\mathrm{a}}$

$5 \quad{ }^{a}$ Department of Environmental Engineering, Technical University of Denmark, 2800

6 Kongens Lyngby, Denmark; ${ }^{b}$ Climate adaptation and Green Infrastructure, Ramboll,

72300 Copenhagen S, Denmark; ${ }^{c}$ VandCenter Syd, 5000 Odense, Denmark

$8 \quad *$ corresponding author: Julie Skrydstrup; Technical University of Denmark, Department

9 of Environmental Engineering, Bygningstorvet, Building 115, 2800 Kongens Lyngby,

10 Denmark; Phone: +45 452514 62; Email: jusk@env.dtu.dk; ORCID: 0000-0002-1781-

115105

12 Herle Mo Madsen; Technical University of Denmark, Department of Environmental

13 Engineering, Bygningstorvet, Building 115, 2800 Kongens Lyngby, Denmark; Phone:

14 +45 452514 39; Email: hermom@env.dtu.dk; ORCID: 0000-0003-3557-2386

15 Roland Löwe; Technical University of Denmark, Department of Environmental

16 Engineering, Bygningstorvet, Building 115, 2800 Kongens Lyngby, Denmark; Phone:

17 +45 452516 94; Email: rolo@env.dtu.dk; ORCID: 0000-0002-5549-5456

18 Ida Bülow Gregersen; Climate adaptation and Green Infrastructure, Ramboll,

19 Hannemanns Allé 53, 2300 Copenhagen S, Denmark; Phone: +45 516153 15; Email:

20 ibg@ramboll.dk; ORCHID: 0000-0001-9415-8287

21 Agnethe Nedergaard Pedersen; VandCenter Syd, Vandværksvej 7, 5000 Odense,

22 Denmark; Phone: +45 611493 10; Email: anp@,vandcenter.dk; ORCID: 0000-0002-

$23 \quad 8254-4196$

24 Karsten Arnbjerg-Nielsen; Technical University of Denmark, Department of

25 Environmental Engineering, Bygningstorvet, Building 115, 2800 Kongens Lyngby,

26 Denmark; Phone: +45 452514 50; Email: karn@env.dtu.dk; ORCID: 0000-0002-622127 9505 
28 Incorporating objectives of stakeholders in strategic planning of urban

29 water management

30

31 Acknowledgement

32 This project was funded by Innovation Fund Denmark through the Water Smart

33 Cities Project (Grant no. 5157-00009B). We wish to thank Odense municipality,

34 VandCenter Syd (VCS Denmark), Ramboll and KLIKOVAND for aiding us in the data

35 collection. We would also like to thank Shane Carnohan and Ursula S. McKnight from

36 DTU Environment, for their valuable feedback on our manuscript. We declare no

37 conflict of interest.

38

39

40

41

42

43

44

45

46

47

48

49

50

51

52

53 


\section{Incorporating objectives of stakeholders in strategic planning of urban water management}

Urban water management (UWM) strategies are difficult to implement in the urban space due to conflicting professional objectives and lack of communication tools. We explore stakeholders, objectives and indicators for urban water management and urban planning to make UWM relevant for other urban disciplines. Stakeholder analysis was applied to systematically identify stakeholders and their objectives by screening literature published in professional journals and conference proceedings. The literature study was supplemented with three workshops. Similar sets of planning objectives and stakeholders were identified in the two analyses. 14 stakeholders were identified, from the utility to legal stakeholders. We identified 17 objectives and nine sub-objectives, that can be divided into four overall groups; welfare for citizens, environmental protection, economic growth and technical objectives. Our results are relevant for a variety of UWM projects, providing a common terminology when discussing objectives between stakeholders and enabling an exploration of multifunctional UWM strategies.

Keywords: stakeholder analysis; planning objectives; structured decision-making; urban water management; urban planning

\section{Introduction}

Urban water management (UWM) is challenged by climate change and urbanization (Fratini et al., 2012b; Stahre, 2006). Climate change increases the frequency and intensity of rain events in Northern Europe (Arnbjerg-Nielsen, 2012; Larsen et al., 2009) and urbanization decreases the permeability of the city and increases the density of people (Kaspersen et al., 2017). The result is decreasing water quality, increasing flood risk and decreasing treatment efficiency at the WWTP, threatening the environment and well-being of urban populations.

The 1992 Rio Declaration recognized integrated and holistic approaches as a promising pathway to sustainable solutions. Such approaches have been applied to 
water management (Casal-Campos et al., 2015; Makropoulos et al., 2008), with terms

84 like "Livability" and "Resilience" emerging (Hansen et al., 2019), based on the UN's Sustainable Development Goals (UN, 2015). Strategies have shifted from having one objective (e.g. reduce risk of flooding), to multiple objectives (e.g. recreation and biodiversity) and have taken on names such as Sustainable Urban Water Management (SUWM) (Belmeziti et al., 2015; Larsen and Gujer, 1997). This shift has emphasized the potential benefits UWM provides for external stakeholders (Fletcher et al., 2015). Multi-functionality of strategies is thus seen as a means for obtaining resilience, sustainability and liveability in urban areas, which can be enhanced through spatial planning (Hansen et al., 2019; Meerow and Newell, 2017). Planning in urban areas is complex. Space is a limited resource (Fratini et al. 2012), where many stakeholders with different objectives act under different funds and legislation (Yazdanfar and Sharma, 2015). Several studies report on the importance of including stakeholders in planning to increase the possibility of a successful project (Fratini et al., 2012b; Gregory et al., 2012; Huntjens et al., 2012; Lienert et al., 2013; Tompkins et al., 2008; Yazdanfar and Sharma, 2015). Thus, an interdisciplinary planning process with active stakeholder involvement is required (Geldof and Stahre, 2004). However, this process is jeopardized by communication problems, including both a lack of agreement on objectives and terminology, and a frame for discussing risk levels and uncertainty (Ferguson et al., 2013; Refsgaard et al., 2013). This results in stakeholders choosing different types of technology and hinders or delays the execution of projects (Fratini et al., 2012b; Madsen et al., 2018). Objectives for UWM as part of the urban planning process are often defined either as quantitative fixed frameworks using monetary valuation or holistic qualitative

107 frameworks using narratives as a guiding principle. Examples of monetary valuation 
108 include BeST (Horton et al., 2019), the green infrastructure valuation toolkit (Green

109 Infrastructure Valuation Network, 2013), and the INFFEWS Value tool (Iftekar et al.,

110 2019). These tools help to convey information to many different stakeholders (Chan et

111 al., 2012; de Groot et al., 2010; Gómez-Baggethun and Barton, 2013; Turner and Daily,

112 2008). However, it is often difficult to identify how objectives were derived and

113 connected to relevant stakeholders. Examples of qualitative frameworks include One

114 Water (US Water Alliance, 2016) and Water Wise Cities (IWA, n.d.). While holistic in

115 their formulation, such frameworks may be difficult to apply on specific projects. This

116 is due to their formulation as water strategies, rather than objectives reaching

117 stakeholders that are not interested in water. There is a need to bridge between these

118 two approaches, by revisiting stakeholders, objectives and indicators for urban water

119 management. The goal should be to create a common problem framing that can be used

120 as a basis for economic assessments while simultaneously recognizing the differences

121 between stakeholders (Ferguson et al., 2013).

122 Literature linking stakeholders and objectives of UWM exists (Fratini et al.,

123 2012a; Madsen et al., 2018). However, these studies did not focus on systematizing the

124 identified objectives. In some cases means were not distinguished from ends, and some

125 important stakeholders, representing different departments of the municipality with

126 competing objectives, were not identified. Generally, in water management only very

127 few studies have connected stakeholders, objectives and indicators for quantification

128 (e.g., Horton et al. (2019); Lienert et al. (2015)), and to our knowledge, no such studies

129 exist that specifically address the interference and synergy of UWM with urban

130 planning.

131 We were inspired to explore this research gap by the work Lienert et al. (2015).

132 They used a systematic framework to find stakeholders, objectives and indicators (to 
133 quantify objectives) related to water supply and wastewater disposal infrastructure in

134 Switzerland (Lienert et al., 2015). Objectives and indicators were found through several

135 face-to-face interviews and a workshop. The study provided a comprehensive overview

136 of objectives in a transparent manner, but there was no link to broader urban planning,

137 flood risk management objectives, or multifunctional spaces. These are the key reasons

138 why SUWM are favoured by stakeholders with little interest in water, as discussed by

139 Fletcher et al. (2015).

140 The aim of this article is to explore the diversity of stakeholders, objectives and

141 indicators within urban water management and urban planning. We aim to lay out a

142 reproducible and transparent method that can connect stakeholders with planning

143 objectives to assist the identification of potential stakeholders and collaborations in the

144 development of multifunctional UWM strategies. Results will be generic and are

145 expected to form a basis for stakeholder assessments in a wide range of UWM projects,

146 which can then be adapted to a specific project.

\section{Methodology}

\section{$148 \quad$ Scope of study}

149 Our aim was to extend the work of Lienert et al. (2015) both in terms of focus area and

150 methodology. In terms of focus, we identify the stakeholders and objectives that should

151 be considered in a context where urban water management is increasingly embedded

152 into more general urban planning. In terms of method, we differ from Lienert et al.

153 (2015) by suggesting an explicit method for liturature screening instead of face-to-face 154 interviews.

155 The work of Lienert et al. (2015) used elements of structured decision making

156 (SDM) (Gregory et al., 2012) to derive stakeholders and planning objectives. SDM is a 
157 way of organizing and understanding complex problems. It is a transparent, inclusive and organized approach of generating and evaluating different strategies with respect to values of stakeholders and potential consequences. This distinguishes SDM from other

160 decision frameworks, e.g., solely scientific or consensus-based. SDM guides decision-

161 makers (DMs) by giving input to "what matters" and to whom, as well as consequences

162 of implementing a given strategy. It furthermore supports development of a common

163 understanding of the problem at hand (Gregory et al., 2012), aiding in solving several of

164 the challenges listed in the introduction, including neglect of important stakeholders and 165 miscommunication.

166 Objectives and indicators are important elements in the context of SDM and are

167 used to identify and evaluate strategies. Objectives are essentially the outcomes that

168 stakeholders seek in the decision context, while indicators quantify objectives and make

169 them measurable. Objectives are often formulated as concise statements of interest,

170 informed by one or more stakeholders, that might be affected by strategies (Gregory et

171 al., 2012). Bond et al. (2010) states that an objective template, or list of objectives,

172 should be consulted (if it exists) to ensure a more holistic identification of objectives.

173 There are six core steps of SDM (Figure 1) but in this paper we focus on the

174 second step of SDM, where stakeholders, objectives and indicators are identified and

175 defined. The generated results are used as direct input for the second step of SDM

176 (Figure 1-A) and provide a foundation for DMs to identify relevant stakeholders and

177 planning objectives. Our method (Figure 1-B) can be replicated within any field of

178 interest, where a foundation for discussing stakeholders and objectives is needed.

179 [Figure 1 placed around here] 


\section{Research design}

181 Our research design is rooted in qualitative research and combines stakeholder analysis

182 (following the key steps suggested in Reed et al. 2009), with a systematic literature

183 screening validated with workshops (Figure 2).

184 [Figure 2 placed around here]

185 Our study utilized literature published by practitioners, because we wanted to

186 focus on work where practitioners actively participated, to ensure the research will find

187 practical application. Furthermore, practitioners are in an advantageous position to

188 identify stakeholders (Colvin et al. 2016). We chose a confined geographical area

189 (Denmark) and time period (2016-2017) for our primary data, to ensure relevance for

190 current practice and a better foundation for interpreting implicit objectives and

191 stakeholder dynamics using our local knowledge.

192 We applied a predefined coding scheme, which coded the literature into

193 standardized names for stakeholders and planning objectives, ensuring consistent

194 naming and condensed data. The predefined coding scheme was based on our

195 experience and literature. Besides stakeholders and objectives, the scheme consisted of;

196 (1) initial codes for project types, (2) scales (time and space), and (3) planning contexts

197 to see how these affected objectives and stakeholders. Objectives are context specific

198 (Madsen et al., 2016) as preferences change in time and space as society develops and

199 different areas struggle with unique problems. The time scale was chosen to distinguish

200 between short-term projects and long-term projects. The spatial scale captured the

201 extent of each project, distinguishing between local, city, regional and national levels.

202 The coding scheme was allowed to evolve as new data was discovered through the

203 literature screening process (Figure 2). The literature screening stopped when no new 
204 information was obtained. The coding scheme is available in Skrydstrup and Madsen

205 (2019).

206 Stakeholders and objectives identified through the screening process were

207 subsequently validated through a set of workshops (primary data). In addition, we cross-

208 compared with national and global literature to avoid blind-spots (secondary data)

209 (Figure 2). Finally, we tried to interpret our results by predicting stakeholder alliances

210 based on their link to objectives. The following sections will give a more detailed

211 description of data and the different steps.

\section{Data description}

213 In this study we worked with primary and secondary data (Figure 2). We gathered

214 primary data first hand through literature screening and workshops (Table 1). We

215 compared our results from the primary data to already published literature, being both

216 national and global, and denote this secondary data (Table 2). Validation thus consisted

217 of both primary data (workshops) and secondary data (journal articles and existing

218 tools).

219 Primary data

220 We identified journals with a focus on exchange of planning experience and knowledge.

221 We identified EVA-bladet (EVA-B) and Dansk Vand conference proceedings (DVC) to

222 cover the UWM dimension, and Byplan Nyt Magazine (BPN) to cover urban planning

223 (Table 1). We chose these groups of literature, because they are published by well-

224 established organisations, are far-reaching and cover many different issues within

225 UWM and urban planning. We facilitated three workshops to validate literature results.

226 [Table 1 placed around here] 
228 We chose literature themes that represented different aspects of UWM including

229 drinking water, wastewater and climate change adaptation. These themes included more

230 specific aspects, such as rainwater harvesting and stormwater management. Literature

231 pertaining to urban planning aspects was prioritized (Table 2). The selected literature

232 overlaps with some of our work, but none of them covers the link between objectives

233 and stakeholders for UWM within the urban planning domain. More details are

234 available in the Supplemental Material (S4).

235 [Table 2 placed around here]

236 The process of extracting, systematizing and interpreting the data was done as

237 suggested by Creswell (2013). Several layers of interpretation were applied. Initially,

238 text sections were extracted with a low degree of interpretation. Text segments were

239 extracted if they contained at least one code or if they contained a new stakeholder or

240 objective (new codes). Subsequently, the data were aggregated through several rounds

241 of coding with increasing degrees of interpretation. Even though we allowed higher

242 degree of interpretation, we still tried to keep as close to the source as possible. As such,

243 the coding was an iterative process, going back and forth between the different degrees

244 of interpretation, securing internal validation.

245 In EVA-B, DVC and BPN (Table 1) we screened 42 articles in total, published

246 in 2016 and 2017 (Dansk Byplanlaboratorium, 2016-2017; DANVA, 2016; EVA, 2016-

247 2017). In addition to stakeholders, objectives and indicators, auxiliary information (e.g.

248 project types, spatial scales, time scales and stakeholder roles) was collected, because

249 we expected impacts on the results.

250 Articles were not considered if they described a technology, focused on

251 calculations, or if the project was already screened and no new information could be 
obtained. Additionally, we excluded papers authored solely by researchers to ensure stakeholders and their objectives were grounded in practice. The screening stopped when no additional objectives or stakeholders could be identified. Objectives were structured in a hierarchy to give an overview of objectives, sub-objectives and indicators and thus provide a good foundation for discussions (as in Lienert et al. (2015)) (Figure 3). The hierarchal structure is based on the level of abstraction, where groups/objectives are the highest level of abstraction and indicators the lowest, i.e., they are more detailed and quantifiable (Gregory et al., 2012). The objectives hierarchy was created through an iterative process, with the aim of disentangling and unifying stakeholder's often ambiguous and/or implicit formulation of objectives. We did several rounds with sorting (i.e. removing objectives that were not potential project outcomes, but instead means), condensing (i.e. merging objectives with similar meaning) and grouping the coded data (based on objectives with similar aim) (Supplemental Material, S1). Subsequently, the final set of objectives were structured according to their level of abstraction within the identified groups (Figure 3).

267 [Figure 3 placed around here]

Simultaneously, the stakeholders were grouped according to their role in society based on internal group discussions. After the screening we categorized the stakeholder's role in planning based on our own experience and looked for evidence in

271 the final results.

\section{Workshops}

The diversity of the objectives hierarchy and connections between stakeholders and objectives were validated through three workshops (Table 3). Using our network, we recruited participants with several years of experience within their field, covering

276 both water professionals and urban planners. In the first workshop we invited 
consultants with different expertise who could cover a broad range of planning aspects.

278 During this first workshop, most of the stakeholders and objectives were identified.

280 diversity among the groups (Table 3). All workshops lasted approximately three hours

281 and each was held at a different location; a consulting firm, a utility, and a research

282 institute. The sampling stopped after the third workshop, because we did not obtain new

283 information. Since participants in our workshops covered all the relevant professions,

284 we do not have reason to believe our results would have been different with different

285 participants. By the second and third workshop participants were struggling to identify

286 new objectives and indicators.

287 [Table 3 placed around here]

288 The workshops included the following elements:

- In the first session, participants were asked to brainstorm stakeholders and objectives for two simplified and anonymous case studies. These were, a specific plan for a local project and, a strategic plan for a larger urban development area. Both case studies focused on the interaction between UWM and urban planning. To test the diversity of objectives and stakeholders, we did not present the objectives hierarchy nor the list of stakeholders to the participants.

- In the second session, participants were asked to convert a selection of objectives to indicators. Indicator selection was assisted by facilitators, who merged the brainstormed objectives, so participants had time to cover them all. Objectives overlapping in meaning, based on the definition of objectives as described under terminology, were merged. 
302 spatial and temporal scales on objectives and stakeholders. Indicators were not

303 frequently used in UWM and urban planning literature. The workshops therefore placed

304 a particular focus on converting objectives into potential indicators.

305 Workshop sessions were based on group work. Groups were defined beforehand

306 based on the working area/background of the participants. In the first session, we aimed

307 at groups with a high mixture of working areas to create a dynamic atmosphere. In the

308 second session, we aimed at groups with similar working areas. Each group selected the

309 objectives they wanted to work with to promote meaningful discussions about

310 indicators. In each session we aimed at consensus between participants and between

311 groups. We therefore included a follow-up round after each session to ensure consensus

312 between groups and the same understanding of stakeholders, objectives and indicators.

313 Facilitation was kept at a minimum, and only used when a deeper insight was needed

314 (e.g. to clarify the definition of an objective). It was thus the participants eliciting

315 stakeholders, objectives and indicators with little facilitation. We used the coding

316 scheme to compare workshop and literature results, and revised the coding scheme

317 accordingly (Figure 2). The workshop material is available in Skrydstrup and Madsen 318 (2019).

\section{Cross-comparison against secondary data}

320 The cross-comparison against secondary data (Table 2) aimed at validating both the

321 diversity of objectives and the connection of stakeholders and objectives (Table 1). The

322 first cross-comparison was with the first version of the objectives hierarchy (Figure 2).

323 We mainly tested the diversity of objectives, but were also inspired by their

324 categorization of objectives. We never removed objectives based on the cross- 
comparison, but added objectives that appeared in several sources. Ultimately, the

326 comparison resulted in a condensed hierarchy.

focused on validating stakeholder's connection to objectives. Also in this comparison,

329 no connections were removed. The comparison was purely qualitative and based on a

330 limited number of studies (Table 2).

\section{Interpretation of alliances}

332 In a final step, we tried to identify stakeholders with a majority of objectives in

333 common. We defined similarity by means of the Hamming similarity measure (Garg

334 and Kumar, 2018; Hanneman and Riddle, 2005). The Hamming similarity measure compares two vectors (i.e., two stakeholders) by counting the number of times they are similar and divides the count with the length of the vectors. We define alliances as

337 group of stakeholders (minimum three) with at least $80 \%$ similar connections. Results

338 are described qualitatively and validated with our own expectations and already studied

339 alliances. Forming realistic alliances from our primary data is a way of validating the

340 literature and workshop results. The exact results are available in Skrydstrup and

341 Madsen (2019).

\section{Results and discussion}

343 The initial stakeholder analysis by literature screening resulted in 22 stakeholders and

34443 objectives. After the workshops eight additional stakeholders were identified and

345 some objectives reformulated. The list was condensed to 14 stakeholders, 17 objectives

346 and 9 sub-objectives following internal group discussions, cross-comparison with

347 secondary data, and iterative condensing and sorting. The final coding scheme along

348 with descriptions of stakeholders and objectives are available in Skrydstrup and Madsen 
349 (2019). The following sections will describe stakeholders, objectives and indicators.

350 The final section will discuss how the results can be applied in planning of UWM.

\section{$351 \quad$ Stakeholders and their objectives}

\section{$352 \quad$ Stakeholders}

353 We identified 14 stakeholders (Figure 4). Health and social aspects were added in the

354 workshops ("Municipality - Health \& Social”), whereas "Politicians", "Legal”

355 stakeholders, and "Foundations", were only identified in the literature screening. These

356 stakeholders were also not mentioned in Madsen et al. (2018), which used snowball

357 sampling to identify active stakeholders for climate change adaptation. Our workshop

358 participants work with planning and implementation of water management, and are

359 therefore rarely in contact with "Politicians" and "Legal" stakeholders. This is because

360 the legal requirements are already nested in municipalities, while politicians are

361 reflected in the stated objectives of civil society and/or municipality (Fratini et al.,

362 2012b). However, "Politicians" and "Legal” stakeholders are important for changing

363 objectives over time, i.e., by implementing new regulations.

364 Compared to our references (Fratini et al., 2012b; Madsen et al., 2018) we

365 identified "Foundation", "Legal" and "Investors" as additional stakeholders. It is

366 essential to consider these stakeholders in a planning process, as they set the legal and

367 financial boundary conditions for UWM. In addition, both studies included the

368 municipality as a single organisation, but the municipality consists of several divisions

369 with different objectives. Our analysis divided the municipality in four departments

370 (Figure 4), as was suggested consistently during the workshops. Further differences

371 between our references (Table 2) and our results are described in Supplemental Material 372 (S4). 
374 groups are found in Supplemental Material, S3). Based on internal group discussions,

375 Figure 4 indicates the direction of influence. In the middle of the planning process is the

376 DM, often mentioned in literature with a "budget to spend" and as the entity responsible

377 for developing, planning and establishing strategies, often in collaboration with "Utility

378 - Water" and "Consultants". The DMs are, for example, responsible for identifying

379 stakeholders, negotiating potential collaborations, and planning objectives. The

380 municipality is the typical DM in UWM and spatial planning (Figure 4) (Ministry of

381 Environment, 2012). DMs are influenced by all the other groups in the planning process

382 (Figure 4). On one side are knowledge providers (i.e., consultants). On the other side are

383 stakeholders that sets the boundaries of projects by legislation. Finally, there is the

384 group of opportunities and risks, here called "potential collaborators or opponents".

385 In some cases, stakeholders can switch groups. For example, if municipal

386 departments do not work together on a project, they may act as "potential collaborators

387 or opponents" or as "setting the boundaries" for each other.

388 [Figure 4 placed around here]

389 Objectives

390 The 17 objectives and nine sub-objectives were structured in a hierarchy (Figure 5).

391 There was an obvious grouping of objectives into "Welfare for citizens",

392 "Environmental protection" and "Economic growth", in agreement with the three

393 pillars of sustainability (UN, 1992). "Welfare for citizens" covers objectives that

394 enhance livability, a word often mentioned as single objective, but in fact, composed by

395 many of the objectives in this group (Figure 5). Aesthetics, recreation, mobility, safety

$396 \&$ security and education are all components of livability. Health and well-being as well 
as connectedness (the feeling of belonging to an area) and occupation are also part of

398 welfare. "Environmental protection” contains objectives of good water quality,

399 protecting resources and protection of nature (e.g., increasing biodiversity, protecting

400 coast lines). "Economic growth" contains objectives of business development and low

401 cost (investments, operation and maintenance, tangible damages from floods, etc.) that

402 ensure economic growth.

403 Finally, we decided to add an additional group with "Technical objectives",

404 directly addressing water infrastructure. These are central for utility companies, who are

405 key stakeholders in UWM. For example, supply safety, i.e., ensuring safe and reliable

406 drinking water and removal of wastewater, is the core objective of any water utility

407 (Belmeziti et al., 2015). This is a key service to society (Ferriman, 2007), even though it

408 is often taken for granted. Technical objectives ensure that new water infrastructure is;

409 integrated with existing infrastructure, flexible for future changes, ensures supply

410 safety, and is designed for simple and transparent management (Figure 5). These

411 technical objectives can be viewed as means to achieve higher level objectives, such as

412 health and well-being or good water quality. We decided to keep them as separate

413 objectives, because they are practical preconditions for the design of water

414 infrastructure and they appear in some of our secondary data (Ferguson et al., 2013;

415 Harris-Lovett et al., 2019, 2018; Lienert et al., 2015). These are often also based on

416 technical and legal constraints and hence have a different form than the other three

417 groups. The technical objectives were derived from a decision support tool developed

418 by one of the biggest utilities in Denmark (VCS Denmark, 2017) (Table 2).

419 [Figure 5 placed around here]

420 BeST covers roughly the same groups of objectives as found in our study, but

421 considers a mix of very specific objectives (e.g., rainwater harvesting and pumping 
wastewater) and more abstract objectives that match our objectives (e.g., education,

423 health and water quality). Unlike BeST (Horton et al., 2019), we also include objectives

424 of connectedness, occupation, transport time and technical objectives. In addition,

425

426

427

428

430

431

432 mobility objectives are not seen in PLASK 3.0, Lienert et al. (2015), Harris-Lovett et al. (2019, 2018), Ferguson et al. (2013), Kuller et al. (2017), Fratini et al. (2012b), Madsen et al. (2018) and only very limited in VCS Denmark (2017) and BeST (Horton et al., 2019). However, mobility appeared most frequently in the literature screening and was mentioned at all three workshops, both as a benefit and threat. Mobility is a public service and an essential aspect of spatial planning (Meurs and Haaijer, 2001). Further differences between secondary data (Table 2) and our results are described in Supplemental Material (S4).

\section{Stakeholders and their connection to objectives}

Table 4 summarizes how often different objectives were linked to stakeholders in the screened literature and workshops (i.e., our primary data). Our sampling strategy aimed at capturing the diversity of planning objectives and stakeholders. The counts can therefore not be interpreted as the strength of a connection, but merely as an indication of the most frequent connection between stakeholders and objectives found in the primary data.

In addition to validating the objective-stakeholder connections, new connections were found in the workshops. For example, there were intuitive connections missing for "Municipality - Traffic \& Roads", such as reducing traffic disturbances, which were captured in the workshops. Similarly, the workshops also added new objectives of transport safety and reducing traffic noise that affect the "Civil society".

[Table 4 placed around here] 
Some of the connections between objectives and stakeholders are intuitive and

447 can be recalled in other literature. For example, the "Utility - Water" is interested in

448 increasing flood safety (service levels), keeping their costs low and ensure good water

449 quality for recipients. These are considered "traditional" objectives for water utilities

450 (Fratini et al., 2012b). In our study, the utility was also connected to objectives of

451 recreation, reduction of traffic disturbances (mobility), health, and education. While the utility's objectives are not part of the repertoire of stakeholders outside UWM, the opposite is quite true. This was evident in both the literature screening, the utility decision support tool and Madsen et al. (2018). Dominguez et al. (2009) found the Swizz utilities to have social and environmental objectives as requirements to be fulfilled, but not as the primary focus, which bears similarity to our results. The "Consultants" covered both engineering consultants and other types of consultants (e.g., architects), resulting in connections to most welfare objectives (except occupation) and the entire environmental protection group (Table 4). Madsen et al. (2018) found similar diversity.

"Commercial” stakeholders are mentioned in nine articles, with different objectives in almost every article and most new objectives after the workshops. This most likely illustrates local business interests. planning”), covers all of the welfare and economic objectives. These stakeholders are

466 responsible for the physical development of the urban space (Fratini et al., 2012b),

467 which means accommodating many different needs from society. Connections between "Municipality - Health \& Social” and "Municipality - Traffic \& Roads” were rarely visible in the articles (contrary to the workshops), so their interests might be covered by 
City planning" and "Municipality - Water \& Environment" in the selected literature

472 (Table 1). We assumed that "Municipality - Water \& Environment" was implied, if the municipality (with no further specification) was mentioned in EVA-B or DVC, while mentions in BPN were assumed to refer to "Municipality - City planning”. dependent on context, spatial scale and time. We embedded this in our research design,

477 by including these factors in the literature screening and in the workshops. However, we did not find any patterns in our data relating to the defined spatial scales and temporal scales. One reason may be that most articles in the literature screening were operating on city scale with long time horizons, which could indicate that these projects are more interesting from a planning perspective. The final coding scheme is available in

482 Skrydstrup and Madsen (2019).

\section{Stakeholder alliances}

484 We identified stakeholders with most objectives in common, as an indication of their 485 potential for forming alliances. This was a way of validating the results by 486 reconstructing meaningful alliances. We acknowledge that alliances are complex and 487 thus also based on other conditions such as, money/procurement, governmental structures, personal relationships and social networks (Lee and Cavusgil, 2006; Love et al., 2010). We identified eight potential alliances, in which all stakeholders shared a majority of their connections to objectives (Supplemental Material, S5). This section

491 focuses on the description of the two key alliances. More alliances can be identified based on the raw data (Skrydstrup and Madsen, 2018). 
497 Agency". These stakeholders have recreation, mobility and health \& well-being in common. It is the common link to connectedness, business development and low costs that makes the alliance unique. The alliance is typically seen when political strategies

500 and municipal objectives are merged into local developments plans in spatial planning 501 in Denmark (Ministry of Environment, 2012).

502 The second alliance is between "Municipality - Water \& Environment", "Utility

503 - Water" and "Consultant". They share objectives that include mobility, safety \&

504 security, nature and low costs (Table 4). However, it is the common interest in

505 aesthetics, safety \& security and water quality that distinguishes the alliance. Also of

506 note is the missing interest in occupation. The "Consultant" group has a lower

507 similarity with the "Utility - Water" objectives (Table 4). However, the "Consultant",

508 "Utility - Water" and "Municipality - Water \& Environment" usually work closely

509 together on climate change adaptation projects, where citizen involvement is

510 increasingly becoming a part (Madsen et al. 2018; EVA, 2016-2017; DANVA, 2016).

511 Alliances are expected to be sensitive to the local context and how a project

512 addresses planning objectives. Having similar objectives, does not mean stakeholders

513 agree on how they should be addressed. Nevertheless, the results give a preliminary idea

514 of potential project partners and how other stakeholders might be encouraged to

515 participate in strategic planning.

\section{$516 \quad$ Indicators}

517 We screened for indicators to quantify planning objectives, both in the literature and

518 during the workshops. However, many stakeholders do not commonly apply indicators

519 to measure the success of planning. Indicators could be identified in three out of 24

520 BPN articles and four out of 18 articles in EVA-B and DVC. Similarly, the workshop 
521 participants were struggling to identify meaningful indicators outside their area of

522 expertise, but did manage to identify indicators for well-known planning objectives

523 within their own field. However, participants did not agree on either their importance,

524 or their specification. Some workshop participants were concerned that indicators would

525 divert planning efforts towards optimizing numbers (e.g., economic).

526 Based on the sparse representation of indicators in our data, we could not

527 conclude on the representativeness of our results and excluded it from further analysis.

528 This result underlines the need for a better understanding of the connection between

529 indicators and planning objectives for both practitioners and research, as well as a

530 continued dialogue between stakeholders. The identified indicators and coverage of the

531 objective's hierarchy (Figure 5) are included in Supplemental Material, S7.

\section{Application in decision-making}

533 Every planning process is initiated by drivers, e.g., a need to reduce floods, reduce

534 crime or improve water quality in a river. Returning to our study's contributions to the

535 SDM approach(Gregory et al., 2012) (Figure 1), it is the second step where

536 stakeholders, objectives and indicators are defined. Our study provides a list of

537 stakeholders relevant for UWM and urban planning (Figure 4), from which DMs can

538 identify stakeholders relevant for their project. Furthermore, we developed an objectives

539 hierarchy (Figure 5). Similar to Fratini et al. (2012b) and Madsen et al. (2018), and

540 confirmed that stakeholders speak about objectives differently (Supplemental Material,

541 S2). The objectives hierarchy can provide a starting point for discussion by giving an

542 initial list of objectives to consider (Figure 5). This can help to ensure a common

543 language and understanding of objectives that can support the identification of a

544 common direction. This requires that stakeholders actively discuss what the objectives 
545 in the hierarchy actually mean within the decision context (e.g. Is "good water quality"

546 related to the recipient stream and/or groundwater resources?).

547 Step 2a and 2b (Figure 1) are coupled by Table 4, connecting stakeholders with

548 objectives. The list is generic, and the project context will thus exclude irrelevant

549 stakeholders and objectives. This simplifies the process of moving iteratively within the

550 second step of SDM. Finally, our results feed directly into the third step of SDM, where

551 strategies (i.e., "alternatives" as used by Gregory et al. (2012)) are developed. All steps

552 should be approached iteratively.

553 In summary, our study simplifies the work of future planning studies while

554 explicitly recognizing the different objectives of the stakeholders. We provide a

555 practical starting-point for use within time-limited planning processes that can

556 streamline communication between stakeholders and initiate exploration of innovative

557 UWM strategies. Our results provide a foundation for which DMs can identify, discuss

558 and prioritize objectives, which can later be coupled to monetary valuation, as decisions

559 are often based on budgetary constraints. On a scholarly note, we have illustrated a

560 reproducible and transparent method for elucidating generic connections between

561 stakeholders and objectives. We focused on UWM and urban planning, but the

562 developed method (Figure 2) could also be applied in other fields, (e.g. energy supply)

563 to produce similar results (i.e. an objectives hierarchy applicable within SDM).

\section{Limitations}

565 We could not find any patterns in objectives and stakeholders for different spatial-

566 temporal scales in our primary data. City wide projects with long time horizons

567 dominated the primary data sources, making them unfit for assessments of scale

568 dependencies. Furthermore, interpretation in the literature screening was unavoidable as

569 objectives and link to stakeholders often were ambiguous. Similar issues were found in 
570 the workshops, as participants were struggling to set-up objectives according to the

571 definitions in the section describing the scope of this study. Expanding the number of

572 workshops with the same participants, or extending the educational session before

573 group work, might help participants separate objectives (ends) from the means to

574 achieve them. We chose literature within a confined geographical area (Denmark) and

575 time period (2016-2017). We compared with secondary literature from other countries

576 in Europe and Australia to ensure diversity and no blind spots. We believe the diversity

577 of stakeholders and objectives are useful for both local- and larger planning scales

578 within a European context, but we cannot speculate about relevance outside Europe,

579 where the dynamics of stakeholders and objectives are different.

\section{Conclusion}

581 In this study, we focused on exploring the diversity of stakeholders and objectives in

582 planning of UWM in the context of urban planning. We developed a hierarchy of

583 planning objectives, as well as an overview of stakeholder's link to the objectives. The

584 results were derived and documented in a transparent manner.

585 We identified 14 stakeholders that are relevant to consider, as well as 17

586 planning objectives and 9 sub-objectives. These could be divided into welfare for

587 citizens, environmental protection, economic growth and technical objectives. Unlike

588 previous studies, we also identified stakeholders that define legislative and financial

589 boundaries as important for strategic planning of urban water management. In addition,

590 the identified planning objectives are more generic and cover a broader scope of urban

591 planning.

592 We identified few indicators in the literature screening, and in the workshops, as

593 participants were struggling to connect indicators to objectives. We thus concluded that

594 most stakeholders do not tend to use indicators in planning, and they do not agree on 
their definition, or their importance. The process of developing indicators is on-going,

596 and future research should continue to bridge the gap between indicators and objectives. Similar to other studies, our literature screening suggests communication

difficulties, where stakeholders speak about planning objectives differently. Our results

can help avoid miscommunication when speaking about planning objectives by ensuring standardized terms for the different objectives. Thus, our work also provides input for the second step of structured decision making (SDM) in urban water management and assists in identifying potential collaborators. For example, we identified the utility to most likely form alliances between the water and environmental division of the municipality, and civil society; an alliance typically seen in climate change adaptation projects. In general, our methodology allowed us to construct meaningful objectives, as the stakeholders that participated in workshops often went beyond those identified in the secondary data. could, for example, involve different prioritizations of the objectives. However, they

610 provide a starting point for discussion in other locations, as well as support for holistic

611 management where multiple stakeholders and objectives are considered jointly.

\section{References}

613 Arnbjerg-Nielsen, K., 2012. Quantification of climate change effects on extreme 614 precipitation used for high resolution hydrologic design. Urban Water J. 9, 57-65. 615 https://doi.org/10.1080/1573062X.2011.630091

616 Ashley, R.M., Horton, B., Digman, C.J., Gill, E., 2013. Demonstrating the multiple 617 benefits of SuDS - A business case - Literature Review, CIRIA. London.

618 Belmeziti, A., Cherqui, F., Tourne, A., Granger, D., Werey, C., Le Gauffre, P., Chocat, 619 B., 2015. Transitioning to sustainable urban water management systems: how to 620 define expected service functions? Civ. Eng. Environ. Syst. 32, 316-334. 
Bond, S.D., Carlson, K.A., Keeney, R.L., 2010. Improving the generation of decision objectives. Decis. Anal. 7, 238-255. https://doi.org/10.1287/deca.1100.0172

Casal-Campos, A., Fu, G., Butler, D., Moore, A., 2015. An Integrated Environmental Assessment of Green and Gray Infrastructure Strategies for Robust Decision Making. Environ. Sci. Technol. 49, 8307-8314. https://doi.org/10.1021/es506144f

Chan, K.M.A., Satterfield, T., Goldstein, J., 2012. Rethinking ecosystem services to better address and navigate cultural values. Ecol. Econ. 74, 8-18. https://doi.org/10.1016/j.ecolecon.2011.11.011

Colvin, R.M., Witt, G.B., Lacey, J., 2016. Approaches to identifying stakeholders in environmental management: Insights from practitioners to go beyond the "usual suspects." Land use policy 52, 266-276. https://doi.org/10.1016/j.landusepol.2015.12.032

Creswell, J.W., 2013. Qualitative inquiry and research design: choosing among five approaches, 3rd ed. SAGE Publications.

Dansk Byplanlaboratorium, 2016-2017. ByplanNyt (Danish journal for exchange of experience in city development). Copenhagen, Denmark.

DANVA, 2016. Dansk Vand conference proceedings. DANVA (Danish water- and wastewater union). Copenhagen, Denmark

de Groot, R.S., Alkemade, R., Braat, L., Hein, L., Willemen, L., 2010. Challenges in integrating the concept of ecosystem services and values in landscape planning, management and decision making. Ecol. Complex. 7, 260-272. https://doi.org/10.1016/j.ecocom.2009.10.006

Dominguez, D., Worch, H., Markard, J., Truffer, B., Gujer, W., 2009. Closing the Capability Gap: Strategic Planning for the Infrastructure Sector. Calif. Manage. Rev. 51, 30-50.

Erik Gómez-Baggethun, David N. Barton, 2013. Classifying and valuing ecosystem services for urban planning. Ecol. Econ. 86, 235-245.

EVA, n.d. EVA Bladet (Danish journal for exchange of experience amongst water engineers). IDA (Danish Engineering Association). Copenhagen, Denmark. 
Ferguson, B.C., Frantzeskaki, N., Brown, R.R., 2013. A strategic program for transitioning to a Water Sensitive City. Landsc. Urban Plan. 117, 32-45. https://doi.org/10.1016/j.landurbplan.2013.04.016

Ferriman, A., 2007. BMJ readers choose the "sanitary revolution" as greatest medical advance since 184. Br. Med. J. 334, 111. https://doi.org/10.1136/bmj.39098.461968.DB

Fletcher, T.D., Shuster, W., Hunt, W.F., Ashley, R., Butler, D., Arthur, S., Trowsdale, S., Barraud, S., Semadeni-Davies, A., Bertrand-Krajewski, J.L., Mikkelsen, P.S., Rivard, G., Uhl, M., Dagenais, D., Viklander, M., 2015. SUDS, LID, BMPs, WSUD and more - The evolution and application of terminology surrounding urban drainage. Urban Water J. 12, 525-542. https://doi.org/10.1080/1573062X.2014.916314

Fratini, C.F., Elle, M., Jensen, M.B., Mikkelsen, P.S., 2012a. A conceptual framework for addressing complexity and unfolding transition dynamics when developing sustainable adaptation strategies in urban water management. Water Sci. Technol. 66, 2393-2401. https://doi.org/10.2166/wst.2012.442

Fratini, C.F., Geldof, G.D., Kluck, J., Mikkelsen, P.S., 2012b. Three Points Approach (3PA) for urban flood risk management: A tool to support climate change adaptation through transdisciplinarity and multifunctionality. Urban Water J. 9, 317-331. https://doi.org/Doi 10.1080/1573062x.2012.668913

Garg, H., Kumar, K., 2018. Distance measures for connection number sets based on set pair analysis and its applications to decision-making process. Appl. Intell. 48, $3346-3359$.

Geldof, G.D., Stahre, P., 2004. The interaction between water and society. Enhancing Urban Environ. by Environ. Upgrad. Restor. 381-394.

Green Infrastructure Valuation Network, 2013. Building natural value for sustainable economic development: The green infrastructure valuation toolkit user guide.

Gregory, R., Failing, L., Harstone, M., Long, G., McDaniels, T., Ohlson, D., 2012. Structured Decision Making: A practical guide to environmental management choices. Wiley-Blackwell, New York.

Hanneman, R., Riddle, M., 2005. Measures of similarity and structural equivalence, in: 
682

683

684

685

686

687

688

689

690

691

692

693

694

695

696

697

698

699

700

701

702

703

704

705

706

707

708

709

710

711

712

Introduction to Social Network Methods. http://faculty.ucr.edu/ hanneman/, Riverside, California, p. 20.

Hansen, R., Olafsson, A.S., van der Jagt, A.P.N., Rall, E., Pauleit, S., 2019. Planning multifunctional green infrastructure for compact cities: What is the state of practice? Ecol. Indic. 96, 99-110. https://doi.org/10.1016/j.ecolind.2017.09.042

Harris-Lovett, S., Lienert, J., Sedlak, D., 2019. A mixed-methods approach to strategic planning for multi-benefit regional water infrastructure. J. Environ. Manage. 233, 218-237. https://doi.org/10.1016/j.jenvman.2018.11.112

Harris-Lovett, S., Lienert, J., Sedlak, D.L., 2018. Towards a new paradigm of urbanwater infrastructure: Identifying goals and strategies to support multi-benefit municipal wastewater treatment. Water (Switzerland) 10. https://doi.org/10.3390/w10091127

Horton, B., Digman, C.J., Ashley, R.M., McMullan, J., 2019. B£ST Guidance Guidance to assess the benefits of blue and green infrastructure using B£ST. CIRIA. London.

Huntjens, P., Lebel, L., Pahl-Wostl, C., Camkin, J., Schulze, R., Kranz, N., 2012. Institutional design propositions for the governance of adaptation to climate change in the water sector. Glob. Environ. Chang. 22, 67-81. https://doi.org/10.1016/j.gloenvcha.2011.09.015

Iftekar, S., Gunawardena, A., Fogarty, J., Pannel, D., Rogers, A., 2019. INFFEWS Value Tool: Guideline (Version 1): IRP2 Comprehensive Economic Evaluation Framework (2017-2019). Melbourne, Australia.

IWA, n.d. The IWA Principles for Water Wise Cities. The International Water Association.

Kaspersen, P.S.; Ravn, N.H.; Arnbjerg-Nielsen, K.; Madsen, H.;, Drews, M., 2017. Comparison of the impacts of urban development and climate change on exposing European cities to pluvial flooding. Hydrol. Earth Syst. Sci. 21, 4131-4147. https://doi.org/10.5194/hess-21-4131-2017

Kuller, M., Bach, P.M., Ramirez-Lovering, D., Deletic, A., 2017. Framing water sensitive urban design as part of the urban form: A critical review of tools for best planning practice. Environ. Model. Softw. 96, 265-282. 
https://doi.org/10.1016/j.envsoft.2017.07.003

714 Larsen, A.N., Gregersen, I.B., Christensen, O.B., Linde, J.J., Mikkelsen, P.S., 2009.

715 Potential future increase in extreme one-hour precipitation events over Europe due 716 to climate change. Water Sci. Technol. 60, 2205-2216.

717 https://doi.org/10.2166/wst.2009.650

718 Larsen, T.A., Gujer, W., 1997. The concept of sustainable urban water management.

$719 \quad$ Water Sci. Technol. 35, 3-10.

720 Lee, Y., Cavusgil, S.T., 2006. Enhancing alliance performance: The effects of contractual-based versus relational-based governance. J. Bus. Res. 59, 896-905. https://doi.org/10.1016/j.jbusres.2006.03.003

Lienert, J., Schnetzer, F., Ingold, K., 2013. Stakeholder analysis combined with social network analysis provides fine-grained insights into water infrastructure planning processes. J. Environ. Manage. 125, 134-148. https://doi.org/10.1016/j.jenvman.2013.03.052

Lienert, J., Scholten, L., Egger, C., Maurer, M., 2015. Structured decision-making for sustainable water infrastructure planning and four future scenarios. EURO J. Decis. Process. 3, 107-140. https://doi.org/10.1007/s40070-014-0030-0

Love, P.E.D., Mistry, D., Davis, P.R., 2010. Price Competitive Alliance Projects: Identification of Success Factors for Public Clients. J. Constr. Eng. Manag. 136,

Madsen, H.M., Andersen, M.M., Ryggard, M., Mikkelsen, P.S., 2018. Definitions of event magnitudes, spatial scales, and goals for climate change adaptation and their importance for innovation and implementation. Water Res. 144, 192-203. https://doi.org/10.1016/j.watres.2018.07.026

Madsen, H.M., Brown, R., Elle, M., Mikkelsen, P.S., 2016. Social construction of stormwater control measures in Melbourne and Copenhagen: A discourse analysis of technological change, embedded meanings and potential mainstreaming. Technol. Forecast. Soc. Change 115, 198-209. for sustainable option selection in integrated urban water management. Environ. 
Model. Softw. 23, 1448-1460. https://doi.org/10.1016/j.envsoft.2008.04.010

745

746

747

748

749

750

751

752

753

754

755

756

757

758

759

760

761

762

763

764

765

766

767

768

769

770

771

772

773

Meerow, S., Newell, J.P., 2017. Spatial planning for multifunctional green infrastructure: Growing resilience in Detroit. Landsc. Urban Plan. 159, 62-75. https://doi.org/10.1016/j.landurbplan.2016.10.005

Meurs, H., Haaijer, R., 2001. Spatial structure and mobility. Transp. Res. Part D Transp. Environ. 6, 429-446. https://doi.org/10.1016/S1361-9209(01)00007-4

Miljøstyrelsen, 2018. Beregningsværktøj - PLASK.Version 3.0. Copenhagen, Denmark. Ministry of Environment, 2012. Spatial planning in Denmark. Copenhagen, Denmark.

Reed, M.S., Graves, A., Dandy, N., Posthumus, H., Hubacek, K., Morris, J., Prell, C., Quinn, C.H., Stringer, L.C., 2009. Who's in and why? A typology of stakeholder analysis methods for natural resource management. J. Environ. Manage. 90, 19331949. https://doi.org/10.1016/j.jenvman.2009.01.001

Refsgaard, J.C., Arnbjerg-Nielsen, K., Drews, M., Halsnæs, K., Jeppesen, E., Madsen, H., Markandya, A., Olesen, J.E., Porter, J.R., Christensen, J.H., 2013. The role of uncertainty in climate change adaptation strategies - A Danish water management example. Mitig. Adapt. Strateg. Glob. Chang. 18, 337-359. https://doi.org/10.1007/s11027-012-9366-6

Skrydstrup, J., Madsen, H.M., 2019. Final coding scheme, definitions of objectives and stakeholders, workshop material and hamming similarity results [WWW Document]. data.dtu.dk. URL https://data.dtu.dk/s/d4ad2a9543756b1d6cd6

Stahre, P., 2006. Sustainability in Urban Storm Drainage. Svenskt Vatten.

Tompkins, E.L., Few, R., Brown, K., 2008. Scenario-based stakeholder engagement: Incorporating stakeholders preferences into coastal planning for climate change. J. Environ. Manage. 88, 1580-1592. https://doi.org/10.1016/j.jenvman.2007.07.025

Turner, R.K., Daily, G.C., 2008. The ecosystem services framework and natural capital conservation. Environ. Resour. Econ. 39, 25-35. https://doi.org/10.1007/s10640007-9176-6

UN, 2015. Transforming Our World: The 2030 Agenda for Sustainable Development. Resolution Adopted by The General Assembly on 25 September 2015.

US Water Alliance, 2016. One Water Roadmap: The Sustainable Management of Life's 
$774 \quad$ Most Essential Resource.

775 VCS Denmark, 2017. VCS Decision Model. Internal document. Odense, Denmark.

776 Yazdanfar, Z., Sharma, A., 2015. Urban drainage system planning and design -

777 Challenges with climate change and urbanization: A review. Water Sci. Technol.

778

72, 165-179. https://doi.org/10.2166/wst.2015.207

779

780

781

782

783

784

785

786

787

788 